\section{Travestismo y transexualidad en las revistas argentinas de medicina, 1971-1982}

\section{Transvestism and transsexuality in Argentine medical journals, 1971-1982}

\section{Anahí Farji Neer}

'Becaria de Formación en Investigaciones Estratégicas, Facultad de Ciencias Sociales/Universidad de Buenos Aires. Ciudad Autónoma de Buenos Aires - Argentina

orcid.org/0000-0002-4953-7672

anahifarji@hotmail.com

Recebido em 17 mar. 2018.

Aprovado em 30 jul. 2018.
FARJI NEER, Anahí. Travestismo y transexualidad en las revistas argentinas de medicina, 1971-1982. História, Ciências, Saúde - Manguinhos, Rio de Janeiro, v.27, n.2, abr.-jun. 2020, p.523538.

\section{Resumen}

El presente artículo aborda los discursos producidos por el campo médico argentino en torno a las iniciativas de corporización de travestis y transexuales en Argentina entre 1971 y 1982. A través del relevamiento y análisis de una selección de artículos publicados en revistas académicas de medicina, se analizan los sentidos que profesionales de la salud asignaron a las mismas antes de la producción de fallos judiciales y normativas nacionales que reconocen la identidad de género como un derecho humano. El análisis realizado permite identificar las particularidades que asumían dichas iniciativas de corporización en el período de estudio, así como las formas en las que el campo médico argentino les imprimió sentidos morales, técnicos y profesionales.

Palabras clave: revistas de medicina; travestismo; transexualidad; género; corporalidad.

\section{Abstract}

This article deals with the discourses produced by the Argentine medical field relating to body transformation initiatives on the part of transvestites and transsexuals in Argentina from 1971-1982. Based on the compilation and analysis of $a$ set of articles published in academic medical journals, it examines the meanings that health professionals assigned to these initiatives prior to the legal rulings and national legislation that recognized gender identity as a human right. This analysis helps identify the particular features of those body transformation initiatives during the period studied, as well as the ways in which the medical field in Argentina attached moral, technical and professional meanings to them.

Keywords: medical journals; transvestism; transsexuality; gender; corporeality. 
$\mathrm{E}^{\mathrm{s}}$ n el presente artículo abordo los discursos producidos por profesionales de la salud en torno a los tratamientos e intervenciones médicas de corporización disidentes de las normas binarias de género en las décadas de 1970 y 1980 en Argentina. Para ello, analizo un conjunto de artículos publicados en revistas académicas de medicina, elaborados por profesionales de la salud de distintas especialidades que se desempeñaban en la ciudad de Buenos Aires y en la ciudad de Rosario. El análisis permite abordar dos procesos diferentes pero interconectados. Los discursos elaborados por estos/as profesionales de la salud son indicadores de los usos de las biotecnologías disponibles bajo formas disidentes de las normas sexo genéricas en el período previo a la consolidación de las categorías del travestismo y la transexualidad en un sentido identitario y/o político. El análisis de esos discursos permite indagar, a su vez, en los sentidos que el campo médico local asignó a dichas iniciativas de corporización antes de la producción de los primeros fallos judiciales que autorizaron cambios registrales de nombre y de sexo, así como de la aprobación de normativas nacionales e internacionales que reconocen la identidad de género como derecho humano.

La hipótesis que guía el presente trabajo afirma que las producciones discursivas del campo médico, plasmadas en revistas de medicina, permiten dar cuenta del proceso de consolidación de las categorías identitarias del travestismo y la transexualidad en un sentido indisociable de prácticas de corporización sexo genérica estables en el tiempo. Sinérgicamente, las producciones del campo médico abonaron a su fijación y estabilización, eslabonándose a discursos de la compasión, de la aberración moral y del peligro social.

Este trabajo forma parte de mi tesis doctoral en la que analicé los modos de regulación social de los tratamientos médicos de construcción corporal trans, específicamente los hormonales y quirúrgicos, antes de la sanción de la Ley de Identidad de Género (ley n.26.743) y las reconfiguraciones emergentes a partir de su sanción. Para ello, comparé cuatro discursos públicos: el médico, el judicial, el activista y el parlamentario entre 1966 y 2015. En el marco de dicha investigación, realicé un relevamiento de artículos publicados en revistas académicas de medicina en el período 1960-1990. En dicho lapso temporal se encontraban vigentes normativas criminalizantes y restrictivas para la circulación en el espacio público de prostitutas, homosexuales, travestis y transexuales. En la ciudad de Buenos Aires, a través de los Edictos Policiales, y en el resto de las provincias a través de los códigos de faltas y contravencionales. Realicé el relevamiento en el archivo de la biblioteca de la Facultad de Medicina de la Universidad de Buenos Aires. Utilicé como palabras clave los términos "travestismo", "transexualismo", "transexualidad" y "cambio de sexo" en los motores de búsqueda correspondientes. Para la elaboración de este trabajo seleccioné tres artículos en los que se plasmaron distintos modos de posicionamiento profesional frente a las prácticas de corporización disidentes de las normas binarias de género en el período abordado. Me centro en las producciones de profesionales de la salud, ya que a partir de mediados de la década de 1990 los discursos médicos ocuparon un lugar clave en las tramas judiciales para acceder a cambios registrales y a tecnologías biomédicas de corporización sexo-genérica por parte de la población travesti y transexual. ${ }^{1}$ Por tal motivo, resulta de interés indagar en los sentidos que el campo médico configuró en torno a las mismas en el período previo.

El artículo se organiza en cuatro secciones. A fin de dar cuenta de la historicidad de las categorías del travestismo y la transexualidad, en un primer apartado abordo las producciones 
del campo sexológico europeo y norteamericano de fines del siglo XIX y mediados del siglo $\mathrm{XX}$ en torno al concepto de "desviación sexual", así como repongo el desarrollo de las tecnologías quirúrgicas de la vaginoplastía, la faloplastia y los "tratamientos hormonales cruzados". Luego, abordo los sentidos que se produjeron en Argentina en el mismo período en el marco de discursos higienistas y criminológicos. En un tercer apartado, realizo un recorrido por distintos trabajos académicos que abordaron los procesos de corporización disidentes del binarismo genérico entre 1950 y 1980 en Argentina, a fin de dar cuenta de las particularidades que dichas prácticas asumían en el período previo a la estabilización de las categorías del travestismo y la transexualidad en un sentido identitario primero y en un sentido político después. En una cuarta y última sección, analizo la selección de artículos publicados en revistas académicas de medicina en torno a las iniciativas de corporización disidentes de las normas binarias de género.

\section{Surgimiento y consolidación de las categorías médicas del travestismo y la transexualidad}

La invención del travestismo y la transexualidad como categorías médicas es resultado del pasaje de una estrategia de represión legal de las prácticas sexuales no heterosexuales y no procreativas a su búsqueda, conocimiento, fijación y regulación. La categoría de la inversión sexual se constituyó como la piedra basal de una serie de intervenciones no ya punitivas sino correctivas (Russo, 2013). En 1886, el psiquiatra alemán Richard von KrafftEbing escribió Psychopathia sexualis. Allí estableció una taxonomía de los distintos cuadros de lo que entendía por desviaciones sexuales. En su esquema no aparecía la separación conceptual actualmente vigente entre las categorías sexo, género y orientación sexual. La idea de una sexualidad natural - heterosexual, orientada a la procreación y directamente relacionada con identificaciones masculinas y femeninas - constituyó el patrón a partir del cual se proponía medir los grados de desviación. Cualquier forma que se distanciara de esa norma era entendida como patológica y luego caracterizada en función de su origen: innato o adquirido. El deseo de vivir acorde a un género distinto al asignado al nacer era entendido por Krafft-Ebing como una ilusión paranoica (Krafft-Ebing, 2006; Leite Jr., 2008). En 1913, Henry Havelock Ellis, médico y psicólogo británico, acuñó el término "inversión sexo-estética", y, en 1920, el de "econismo", para referirse a individuos que se identifican con el "sexo opuesto" no solo en el uso de vestimentas sino también en sus gustos y características emocionales, considerándolo este último como un fenómeno que no debía confundirse con la homosexualidad.

Ya a principios del siglo XX, el médico alemán Magnus Hirschfeld desarrolló una teoría de los "estadios sexuales intermedios". Definió formas ideales de masculinidad y feminidad a partir de cuatro variables: "órganos sexuales", "otras características físicas", "impulso sexual" y "otras características emocionales". Afirmó que la masculinidad y feminidad nunca se condicen con dichos modelos, sino que se desarrollan bajo formas que entremezclan distintos aspectos de esas cuatro dimensiones. En 1910, escribió Transvestites: the erotic drive to cross-dress, en el que creó una categoría autónoma para referirse a personas cuyo estadio sexual intermedio radicaría en el ámbito de las características emocionales. En 
su caracterización del travestismo, el uso de "ropas del sexo opuesto" fue expuesto como un fin en sí mismo, es decir, como una forma particular de subjetividad y no como una expresión de fetichismo sexual (Hirschfeld, 2006; Leite Jr., 2008).

En sintonía con estas concepciones, el término "transexual psíquico" fue acuñado en 1923 por Hirschfeld y retomado en 1949 por el médico estadounidense David Cauldwell (2006). En su texto Psychopathia transexualis, lo describió como una predisposición orgánica hereditaria que, combinada con una crianza disfuncional, podría producir una variedad de efectos psicológicos entre los cuales se encontraría la creencia de pertenecer al "otro sexo".

Bernice Hausman (1995) afirma que el nacimiento de la transexualidad como categoría médica e identitaria asociada a distintos procesos de construcción corporal medicalizados puede ser leído como resultado del avance del conocimiento endocrino y perfeccionamiento de las técnicas quirúrgicas y también de las transformaciones que atravesó la regulación de la sexualidad. En la caracterización elaborada por Hausman, el desarrollo de las tecnologías biomédicas de corporización sexo-genérica tuvo un rol de peso. Las primeras "cirugías de cambio de sexo" se realizaron en la década de 1930 con el objetivo de recrear genitalidades femeninas. Se valieron de las técnicas quirúrgicas desarrolladas a finales del siglo XIX que tenían por objetivo la normalización de bebés nacidos con una corporalidad ambigua o no clasificable bajo los patrones de un modelo sexual binario (Meyerowitz, 2002). La primera vaginoplastía fue realizada en Alemania en 1931 a Lili Elbe, quien murió tras la intervención (Billings, Urban, 1998). Las faloplastias retomaron las técnicas de reconstrucción peneanas aplicadas a soldados mutilados en la Primera Guerra Mundial. El cirujano británico Harold Gillies fue el primero en practicarlas en personas que no presentaban cuadros clínicos de ambigüedad genital ni amputaciones. En la década de 1940, la técnica se complejizó por medio de la incorporación de prótesis peneanas y testiculares sintéticas (Castel, 2001). En 1952, el cirujano danés Christian Hamburger realizó una de las primeras vaginoplastías exitosas a una persona adulta. A partir de la difusión mediática de la intervención, Hamburger recibió consultas desde distintos lugares del mundo, entre ellos, EEUU. El cirujano derivó dichas consultas al endocrinólogo alemán radicado en EEUU, Harry Benjamin (1966), quien comenzó a recetar tratamientos hormonales y a desarrollar su propia teoría sobre la transexualidad.

En lo que respecta a los tratamientos hormonales, a partir de la década de 1930, distintos/ as profesionales se dedicaron a establecer relaciones entre endocrinología, anatomía y psiquismo, retomando los desarrollos de principios del siglo XX del fisiologista austríaco Eugein Steinach. Desarrollaron tratamientos hormonales con el objeto de "curar" las desviaciones sexuales. El endocrinólogo inglés, Michael Dillon, fue el primero en desarrollar los hoy llamados "tratamientos hormonales cruzados" para los casos de "inversión sexual femenina", los que consideraba de carácter innato (Rubin, 2003). Aunque no logró identificar las causas orgánicas de dicha inversión, postulaba que se trataba de casos de ambigüedad sexual y que el tratamiento indicado sería la modificación de los caracteres sexuales secundarios, esto es, todos aquellos que no incluyen la genitalidad.

A partir de la acumulación de estos saberes y prácticas clínicas, Harry Benjamin desarrolló las bases teóricas del diagnóstico y tratamiento clínico del transexualismo 
moderno. Las concepciones de Benjamin se basaron en las teorías conductistas sobre el género que el médico neozelandés, John Money, había desarrollado a partir de sus intervenciones realizadas en la década de 1950 sobre niños y niñas que presentaban cuadros de ambigüedad sexual (Fausto-Sterling, 2006; Kessler, 1990; Preciado, 2008). Para Money, el sexo psicológico o género constituía una dimensión maleable del sexo hasta los dieciocho meses de vida. Una vez pasado ese momento, el género cristalizaría y sería tan inmutable como la propia biología. Los protocolos de tratamiento ideados por Money consistían en determinar y asignar el sexo correcto. Ello requería, en principio, develar el "sexo verdadero", mediante estudios genéticos y hormonales, y luego intervenir los cuerpos a fin de hacerlos funcionales al coito heterosexual penetrativo (Fausto-Sterling, 2006; Kessler, 1990). Estas teorías se basaban en una idea de sexo pluridimensional: cromosómico, gonadal, hormonal y psicológico (Rohden, 2014). En 1966, Benjamin publicó El fenómeno transexual, y, en 1979, los Standards of care for gender identity disorders (SOC), editados por la Harry Benjamin International Gender Dysphoria Association (HBGDA) (Coleman et al., 2012). Allí estableció un método estandarizado para el diagnóstico y tratamiento de la transexualidad. El mismo fue plasmado en los protocolos de atención, implementados por la Clínica de Identidad de Género del Johns Hopkins University Hospital de Baltimore y replicados luego a lo largo del mundo. Las categorías diagnósticas y protocolos permitieron a los/as cirujanos/as realizar dichas intervenciones, ya que el criterio clínico los eximía de ser acusados/as de realizar intervenciones mutilantes (Meyerowitz, 2002). El proceso de diagnóstico buscaba descartar la presencia de otros tipos de cuadros, como la esquizofrenia o la psicosis, y a corroborar tres fenómenos: el sentimiento de pertenecer al otro género, el uso temprano y persistente de vestimentas del sexo opuesto al asignado al nacer sin un sentido erótico y el desprecio hacia el comportamiento sexual homosexual (Bento, 2006). Pasado el proceso de diagnóstico, el tratamiento se componía de tres etapas progresivas: una psicológica, una hormonal y, por último, una quirúrgica.

Desde finales del siglo XX, estos desarrollos se articularon en dispositivos médicos de normalización y corrección de los cuerpos fijados en protocolos y nomenclaturas diagnósticas de alcance mundial. A fines de la década de 1970 y principios de 1980 el diagnóstico de "transexualismo" fue incluido en los manuales de clasificación de enfermedades y trastornos mentales de circulación mundial: el Manual diagnóstico y estadístico de los trastornos mentales (DSM), de la Asociación Americana de Psiquiatría, y la Clasificación Internacional de Enfermedades (CIE), de la Organización Mundial de la Salud. Ello representó la institucionalización de estas concepciones dentro de la comunidad médica global. La CIE 9 de 1978 eliminó la homosexualidad como trastorno mental, pero incluyó el diagnóstico de "transexualismo" al interior del apartado de las "desviaciones sexuales". En 1992 se publicó la CIE 10. Allí, el "transexualismo", juntamente con el "travestismo no fetichista" y el "trastorno de la identidad de género en la infancia", fueron ubicados dentro de la categoría englobadora de "trastorno de la identidad de género". El DSM 3, publicado en 1980, también eliminó la homosexualidad y creó una nueva categoría: el "trastorno de la identidad sexual". Allí incorporó el diagnóstico de "transexualismo" (Di Segni, 2013). El dispositivo de la transexualidad (Bento, 2006) y su naturaleza disciplinadora, normalizadora pero también productiva, habilitó el surgimiento de la transexualidad como categoría 
identitaria y social. Las categorías médicas comenzaron a circular en el campo social y ser apropiadas productivamente por parte de los sujetos.

Teniendo en cuenta estos antecedentes elaborados por el campo médico europeo y norteamericano, a continuación abordo la producción de sentidos en Argentina a principios del siglo XX en torno a las sexualidades y a deseos corporales disidentes de las normas binarias de género en el marco de discursos higienistas y criminológicos.

\section{Inicios de la regulación médica de la sexualidad en Argentina: higienismo y criminología}

La institucionalización de la práctica médica en Argentina estuvo ligada a la conformación de una nación unificada y un Estado centralizado en la segunda mitad del siglo XIX. ${ }^{2}$ Este proyecto civilizatorio se vio influenciado por el positivismo europeo, corriente de pensamiento que otorgaba un lugar central a la gestión científica, objetiva y racional de lo público, especialmente de la cuestión social (Dovio, 2012, p.2). Como afirman Ciancio y Gabrielle (2012), a diferencia del contexto europeo, en Argentina fueron necesidades políticas y sociales antes que intereses de índole científica las que propiciaron el desarrollo del pensamiento positivista. Para la elite gobernante era necesario unificar el territorio en términos políticos e institucionales, e instaurar un sentimiento nacional y de pertenencia compartido. Pero se configuró un ideal de ciudadanía imposible de compatibilizar con la población migrante pobre que se concentraba en conventillos y pensiones cerca del puerto (Dovio, 2012, p.3). Entre los "efectos adversos" del proceso de modernización se encontraban el hacinamiento urbano, los crímenes, la prostitución ${ }^{3}$ y la continua diseminación de prácticas homoeróticas. De este modo, eran entendidos/as como amenaza para el orden en formación no sólo trabajadores/as organizados/as, sino también cualquier forma de vida que pusiera en cuestión el modelo de familia nuclear, conyugal, monogámica y heterosexual.

Higienismo, criminología y reforma moral conformaron una tríada que ocupó un rol central en la gestión de lo público en los inicios del Estado Nación argentino. La "inversión sexual" fue leída allí como una enfermedad degeneradora que amenazaba con su contagio, sobre todo en los espacios designados para la conformación del nuevo ciudadano argentino por excelencia: la escuela y el ejército (Salessi, 1995).

El discurso médico se instaló como grilla epistemológica de producción de saberes sobre lo social a través de los pares sano-enfermo, normal-anormal e inofensivo-peligroso (Nouzeilles, 2000). También sirvió de base al desarrollo de una noción biológica de pertenencia a la nación. La idea de una enfermedad degeneradora - ya sea moral o física - se encabalgó posteriormente a las formulaciones eugenésicas que ingresaron al país en la década de 1930 (Miranda, 2011). Bajo el ideario eugenésico se terminó de integrar la reproducción a la razón de Estado. A partir de allí, se dio una profundización del control de la sexualidad que originalmente había estado puesto en la prostitución y homosexualidad y a partir de la década de 1930 se extendería a las parejas heterosexuales.

Tres referentes del positivismo higienista y criminológico argentino de principios de siglo fueron José María Ramos Mejía, ${ }^{4}$ Eusebio Gómez y Francisco De Veyga. En su 
libro Multitudes argentinas, de 1899, Ramos Mejía acuñó la noción de "invertido sexual" o "guarango" para referir a la adopción por parte de varones de un espectro amplio de hábitos y costumbres entendidas como femeninas y que podían ser corregibles mediante la educación. En 1902 se fundaron los Archivos de Criminología, Psiquiatría y Ciencias Afines, dirigidos por José Ingenieros. Allí colaboraron con sus producciones Ramos Mejía y De Veyga. En 1910, Ingenieros publicó su artículo "Patología de las funciones psicosexuales", en el que estableció una rigurosa y extensa clasificación de perversiones sexuales, basándose la idea de que toda emoción, sentimiento o tendencia sexual que no estuviese vinculado a la finalidad biológica de la reproducción era patológica.

En este marco, Francisco De Veyga $(1902,1903)$ estudió la "inversión sexual". De Veyga fue profesor de medicina legal y el encargado de incluir la enseñanza de la antropología criminal en la cátedra de medicina legal de la Universidad de Buenos Aires a fines del siglo XIX. A partir de dicha incorporación, el Servicio de Observación Alienados del Depósito de Contraventores dependiente de la Policía Federal ofició de extensión de la cátedra de medicina legal. El objetivo era indagar y conocer el psiquismo de los/as contraventores/as, quienes podían acercarse al Servicio de Observación por motivos de salud y no solamente tras ser captados/as por la policía (Ciancio, Gabriele, 2012). Entre los artículos de De Veyga se encuentran "Inversión sexual congénita" e "Inversión sexual adquirida", publicados en los Archivos de Criminología, Psiquiatría y Ciencias Afines en 1902 y 1903 respectivamente. Los artículos tomaban la forma de informes periciales, indagaciones y diagnósticos presentados por los médicos a los jueces. Ello pone en evidencia el tipo de amalgama entre ciencia y derecho de la época. Pero De Veyga se interesaba particularmente por conocer las historias y trayectorias de vida constitutiva de esas identidades a través de la indagación de varias fuentes que podían ser orales, fotográficas o escritas. A través de los relatos de vida de Manón, Aída, Rosita del Plata, Aurora y la Bella Otero, descompuso al travestismo en sus diferentes tipos de inversión, congénita o adquirida. Especificó al interior de esta última tres tipos: profesional, por sugestión y por causa de decaimiento mental (Mendiara, 2002, p.73). En cada uno de los casos descritos y analizados por De Veyga, lo que aparecía como fuerte preocupación era la simulación, el engaño y la mentira.

Estos sentidos fueron los que sustentaron la posterior persecución y criminalización de la "inversión sexual" a través de la incorporación en 1932 de los artículos $2^{\circ} \mathrm{F}$ y $2^{\circ}$ $\mathrm{H}$ de los Edictos Policiales. Los mismos referían a "exhibirse en la vía pública o lugares públicos vestidos o disfrazados con ropas del sexo contrario" y de "incitarse u ofrecerse al acto carnal" respectivamente (Gentili, 1995). Los Edictos Policiales de la ciudad de Buenos Aires constituyeron un código normativo urbano que fijaba penas y multas para aquellas conductas que afectaran la convivencia urbana y que no estuvieran especificadas en el código penal. Por ser penas menores, no configuraban delitos sino contravenciones o faltas. La institución policial era la encargada de elaborar, juzgar y aplicar las ordenanzas policiales (Gentili, 1995). Los Edictos tienen su origen en los Bandos Policiales del Virreinato del Río de la Plata que tenían como fin prevenir los delitos y la corrupción de las buenas costumbres (Gentili, 1995). Como afirma Leticia Sabsay (2011), fueron pensados para regular las acciones en el espacio público. Sin embargo, esa noción de espacio público fue utilizada de forma eufemística para poner en práctica la regulación de una moral social. Edictos y 
códigos de faltas operaron como máquinas de subjetivación, configurando, delimitando y fijando subjetividades particulares segregadas del orden moral vigente (Sabsay, 2011). Junto a las razias policiales, constituyeron las prácticas más evidentes de "violencia moral" institucionalizada, cuyo objetivo era perseguir y controlar la disidencia sexual. A partir de finales de la década de 1940, las provincias comenzaron a elaborar sus propios códigos e incorporaron figuras que también penalizaban la homosexualidad, el travestismo y la prostitución (Simonneto, 2016).

\section{El afianzamiento de las categorías identitarias: tensiones entre el campo médico y el campo social}

Las investigaciones que abordan los procesos de subjetivación disidentes de las normas binarias de género en el período previo a la década de 1990 problematizan la operación de homogeneización de experiencias y trayectorias subyacente a las taxonomías elaboradas por el campo médico (Simonetto, 2018). Distintos trabajos analizaron las variadas y disímiles prácticas de subjetivación y corporización disidentes de las normas binarias de género y la heterosexualidad obligatoria que distan de ajustarse plenamente a las categorías elaboradas por el campo médico. El trabajo de Gabriela Cano (abr. 2009) sobre Amelio Robles en el contexto de la Revolución Mexicana echa luz sobre los procesos de construcción de la identidad masculina en cuerpos asignados al nacer al género femenino sin recurrir a tecnologías ni categorías médicas, sino mediante una performance masculina anclada en la pose, el gesto, el tono de voz y el vestuario. A su vez, da cuenta de procesos de integración social y familiar no disruptivos y de formas de reconocimiento estatal por fuera de dispositivos de validación médico-jurídica. Los trabajos de Bao (1993), Acha y Ben (2004-2005), Insausti (2011) y Simonetto (2018) abordan los encuentros sexuales entre varones de distintas edades y clases sociales, tanto en espacios públicos como privados, entre las década de 1950 y 1980 en Buenos Aires y las perfomances femeninas desplegadas en dichos encuentros. Aún en contextos sociales represivos, estos trabajos afirman que se desarrolló una subcultura sexual homosexual con lugares de reunión específicos, gustos y costumbres. En estas investigaciones, los usos del cuerpo, los gestos y el vestuario disidentes de las normas genéricas binarias no respondían a la noción actual de identidad de género. Las performances femeninas de "las locas" de las décadas de 1960 y 1970 analizadas por Joaquín Insausti (2011) resultan un buen ejemplo de ello. Siguiendo a Insausti, las locas no se reconocían como hombres y tampoco se identificaban plenamente con la feminidad aunque la recreaban en forma paródica. La corporización sexo-genérica de la loca incluía vello corporal, prendas femeninas, maquillaje, pelucas, prótesis de cotillón, muecas y gestualidades femeninas. La performance paródica de la feminidad tenía como fin el encuentro sexual con varones con identificaciones viriles y no la construcción estable de una identidad femenina. Para Insausti (2011), el desarrollo a partir de la década de 1980 en Latinoamérica de una subcultura gay urbana que pretendía emular los modelos europeos y norteamericanos acarreó profundas mutaciones en las configuraciones identitarias y vinculares, tornando inviable la identidad de la loca. Fue en el marco de esa trama de transformaciones sociales que emergió la identidad travesti en Argentina en un sentido identitario primero y político después. 
Siguiendo a Soledad Cutuli (2013), el acceso a las tecnologías biomédicas de construcción corporal - siliconas y hormonas - fueron decisivas en dicho proceso. El término travesti empezó a circular en el contexto argentino a partir de la década de 1960. En un comienzo estuvo ligado a la escena teatral del under porteño, en espectáculos de vedettes que adoptaban una identidad femenina durante los shows. Una vez que las siliconas y las hormonas comenzaron a circular por los espacios artísticos, algunas de estas vedettes adoptaron la categoría travesti en su vida cotidiana. Para la autora, el desarrollo y acceso a las tecnologías biomédicas en los sectores populares fue central para la afirmación del travestismo y la transexualidad como categorías identitarias diferentes a la de la loca, y posteriormente, a la de gay u homosexual. En lo que refiere a las diferencias relativas entre la identidad travesti y la transexual, el antropólogo brasilero Bruno Cesar Barbosa $(2013,2015)$ afirma que en distintos contextos o situaciones las mismas personas pueden adscribir a una u otra identidad dado que existe una continuidad de experiencias y vivencias del cuerpo y la identidad entre ambas categorías. Desde el campo médico, la transexualidad fue definida como mesurada y recatada, a diferencia de los modelos corporales exuberantes ligados al ambiente teatral y prostibulario en el que se desplegaría la identidad travesti. Siguiendo al antropólogo brasilero, quienes adscribían a la identidad transexual solían dominar los términos y narrativas médicas, teniendo en cuenta que para acceder al dominio del léxico del campo médico era necesario haber accedido previamente a la escolarización y otros bienes simbólico-culturales. Estas narrativas eran apropiadas para explicar deseos y sentimientos, y también oficiaban de mapa para la corporización sexo-genérica.

Tomando la hipótesis de la modernización desarrollada por Insausti (2011), el análisis de las producciones discursivas del campo médico, plasmadas en revistas académicas de medicina, permiten dar cuenta del proceso de consolidación de las categorías identitarias del travestismo y la transexualidad indisociables de prácticas de corporización sexo-genéricas permanentes. Las producciones del campo médico abonaron a su fijación y estabilización. Interesa analizar entonces cuáles fueron los saberes y sentidos elaborados por profesionales de la salud en torno a las iniciativas de corporización de travestis y transexuales en momentos previos a la consolidación y estabilización de dichas categorías identitarias. El análisis propuesto tiene por objeto identificar las formas en las que se enlazaron sentidos morales, técnicos y profesionales en torno a dichas iniciativas.

\section{Travestismo y transexualidad en las revistas de medicina argentinas}

Desde mediados del siglo XX en Argentina, la medicina legal y la sexología clínica se constituyeron como los primeros espacios de producción de saberes en torno a las disidencias sexo genéricas. A partir de la década de 1970, el incipiente desarrollo de un saber clínico se desplegó en el marco de los dispositivos legales y policiales que penalizaban ejercer la prostitución, vestirse con "ropas del sexo contrario", y a los/as profesionales de la salud, practicar intervenciones médicas que provocaran la esterilización.

En ese marco, en 1971, el cirujano Arnaldo Yódice escribió en El Día Médico: Periódico Científico e Informativo Ilustrado un artículo titulado "Aguafuerte quirúrgica". Allí relató, 
bajo la forma de una crónica, su experiencia frente al "pedido de extirpación de genitales masculinos" realizado por una persona que, según su relato, en un comienzo aparentaba ser una joven mujer. El médico narró con "asombro" y "estupefacción" los hechos y luego expresó su interés por desentrañar el motivo de dicha consulta.

No pudimos averiguar el origen de semejante aberración, consecuencia psicobiológica de un error de la naturaleza. Porque estos pobres seres, desviados en el orden sensorial, con una mentalidad cercana a la inconsciencia, pretendían la curación de su mal por medio de la mutilación del atributo de su sexo. ¿Cómo era posible semejante monstruosidad? Era la pregunta que nos hacíamos. ... ¡Pobres seres! Ellos no tienen la culpa. La biología les hizo una mala jugada (Yódice, 1971, p.295).

El médico se negó a realizar el pedido solicitado ya que lo concibió como una "aberración" y "monstruosidad", fruto de una pérdida de noción de la realidad. El tono de condena moral se entremezcló en su escrito con una mirada compasiva y exculpatoria. Al movilizar una serie de sentidos compasivos, el profesional matizó su mirada acusatoria o estigmatizante frente al pedido recibido, en sintonía con los desarrollos de los primeros exponentes de la sexología europea.

El relato de Yódice expresa que los sujetos se presentaban en los consultorios solicitando los tratamientos. Dichos pedidos no siempre eran asociados con la criminalidad por el campo médico. En el caso de Yódice, fue cifrado a través de la idea de autoengaño y patología. El profesional entendió que un pedido de tales características no podía más que ser fruto de una pérdida de sentido de la realidad. Las mismas intervenciones que treinta años más tarde serían realizadas en varios consultorios públicos del país, fueron entendidas por Yódice como mutilaciones.

En 1981, la revista La Semana Médica6 publicó el artículo titulado "Aplicación del urocitograma en el estudio endocrino de casos de travestismo y transexualismo". El mismo fue escrito por Leo Lencioni, titular de la cátedra de medicina legal de la Universidad Nacional de Rosario y jefe del cuerpo médico forense de los tribunales provinciales de la misma ciudad. Lencioni había desarrollado la técnica del "urocitograma" para identificar valores hormonales diferenciales por sexo a través del estudio del sedimento urinario. En el artículo expuso los usos de dicha técnica para producir un conocimiento específico sobre los valores hormonales de personas que presentaban "desviaciones sexuales". Su objetivo era desarrollar e instaurar una herramienta pericial. La medicina forense accedía a su objeto de estudio e intervención por medio de la institución policial y su función era producir conocimiento útil a los fines de dicha institución: prevenir y controlar las conductas delictivas y contrarias a la moral pública. Para acceder a sus "casos de estudio", Lencioni (1981, p.511) se valió de su experiencia como médico forense en el Poder Judicial:

En el consultorio de los tribunales provinciales de Rosario, pertenecientes a la segunda circunscripción judicial, examinamos en relación a este trabajo a un transexual y cuatro travestis. El primero se trataba de un hombre de 22 años de edad que se había sometido, en el extranjero, a una operación quirúrgica consistente en la amputación del pene y creación de una neovagina. Fue enviado al consultorio médico por un juez en lo civil dado que había iniciado el trámite con el objeto de lograr el cambio de sexo 
y nombre en los documentos de identidad, lo que finalmente no prosperó. Respecto a los travestis, llegaron a la consulta forense por estar acusados de desorden público y para peritaje psiquiátrico.

Del relato de Lencioni se desprende que, dada la prohibición local, travestis y transexuales comenzaron a acceder a las intervenciones quirúrgicas de modo clandestino o bien en países limítrofes en los que las operaciones eran legales. En base a los interrogatorios practicados, Lencioni (1981, p.511) encontró que en todas ellas "se aplicaban, desde mucho tiempo atrás, altas dosis de estrógenos de depósito por vía intramuscular, los que habían inducido una ginecomastia considerable". En base a dichas prácticas de corporización autoagenciadas, elaboró la categoría de "hombres con desviaciones sexuales que se aplican voluntariamente estrógenos" y analizó los casos en función de cinco variables: edad, ginecomastia aumento del busto - (intensa o moderada), desarrollo genital (hipogonádico, normal o vaginal artificial), valores del urocitograma y observaciones ("travestismo homosexual" o "transexualismo"). En definitiva, Lencioni desarrolló un saber clínico específico en torno a la "desviación sexual" valiéndose de herramientas penales a fin de aportar al conocimiento no solo en los que atañe a sus dimensiones psicológicas sino también fisiológicas para un uso criminológico.

Un año más tarde, la misma revista que había publicado el texto de Lencioni, publicó "La situación del médico frente al tratamiento hormonal de travestis y transexuales. Consideraciones jurídicas, medicolegales y deontológicas", del doctor Luis Alberto Kvitko. El artículo versaba sobre el "tratamiento efectuado por profesionales médicos, que prescriben tratamientos hormonales a estos 'verdaderos enfermos'" (Kvitko, 1982, p.350). Definía a travestis y transexuales como "sujetos que, perteneciendo a un sexo determinado, tienen sin embargo la convicción y el deseo de pertenecer al sexo opuesto [y] buscan la realización de su deseo, sometiéndose a la corrección de la apariencia sexual de su cuerpo por métodos farmacológicos y quirúrgicos" (p.351). En su definición del travestismo y la transexualidad, Kvitko refería a las posibilidades de transformación corporal por medios quirúrgicos y hormonales. Expuso una mirada de sospecha y desconfianza respecto a la aplicación de estas tecnologías biomédicas, a las que entendió como un "adelanto avasallador de las ciencias y de la tecnología" (p.351).

El artículo constataba que los sujetos demandaban tratamientos hormonales a profesionales, quienes en algunos casos daban respuesta a dichos requerimientos. El objetivo del escrito era establecer si dicha prescripción podría constituir un delito en base a las normativas vigentes en aquel momento. Es decir, tenía por objeto delimitar el campo de acción de la práctica médica en base a normas legales, clínicas y morales.

El escrito comenzaba exponiendo las normativas que al momento de producción del artículo se encontraban en vigencia: los Edictos Policiales y las normativas que regulaban el ejercicio de la práctica médica (Código Penal y Ley nacional de ejercicio de la medicina). Luego refería a otros trabajos científicos que afirmaban las posibles consecuencias para la salud derivadas del consumo de estrógenos sintéticos por parte de personas de sexo masculino. Establecía que "son capaces de producir atrofia testicular, así como depresión de la espermogénesis" y que el consumo de altas dosis "pueden originar manifestaciones 
gastrointestinales tales como nausea, vómitos y diarrea" (Kvitko, 1982, p.354). En base a la exposición de argumentos legales y clínicos, Kvitko (1982, p.356) afirmó:

De ninguna manera puede prescribirse a los travestis o trans-sexuales, un tratamiento hormonal, considerando estar obrando ante 'un estado de necesidad' ello debido a que no se está en presencia de un mal inminente, de existencia real y objetiva, que constituya una amenaza de peligro concreta, inminente y actual, comprobada con sólida base científica.

Y proseguía:

La ética, la moral médica, se ven reñidas con la aplicación de estas medidas terapéuticas, que a todas luces contravienen con el espíritu, con el sentido, con el criterio de nuestras normas deontológicas, de necesaria, de imprescindible aplicación, en todos y cada uno de los actos del profesional médico (Kvitko, 1982, p.356).

La negativa a realizar dichos tratamientos se sustentó en dos argumentos. El primero era un axioma propio de la práctica médica: solo debe intervenirse en la medida en que exista una amenaza científicamente comprobada a la salud de la persona que constituya el "estado de necesidad" que lo justifique. El otro era de índole moral: profesionales de la salud deben ajustar sus prácticas a la moral vigente en una época y contexto dado.

En definitiva, los saberes producidos en torno a las corporalidades de travestis y transexuales entre 1970 y 1990 fueron elaborados predominantemente en el marco de la medicina clínica y la medicina legal. Tenían por objetivo controlar un sector de la población entendida como peligrosa o patológica. En ese esquema debía ser resguardado y protegido el orden social y la moral pública, teniendo por base un ideal de verdad natural. Aún adoptando un discurso compasivo no había grados posibles de intervención de la corporalidad si ello contradecía las normas binarias de género. La prohibición médica, legal y moral era taxativa. Las normas legales que regulaban y limitaban el ejercicio médico y las normas morales que las tornaban incorrectas no implicaron el bloqueo del saber en torno a dichos tratamientos e intervenciones. Sí impidieron su disponibilidad para las personas que los solicitaban de forma voluntaria.

\section{Consideraciones finales}

En el presente trabajo abordé los discursos producidos por profesionales de la salud de distintas especialidades en torno a los tratamientos médicos de corporización sexo genérica disidentes de las normas binarias de género en Argentina en el período 1971-1982. Para ello relevé y analicé un conjunto de artículos publicados en revistas académicas de medicina. La hipótesis que motorizó el trabajo afirmaba que las producciones discursivas del campo médico, plasmadas en revistas de medicina, permiten dar cuenta del proceso de consolidación de las categorías identitarias del travestismo y la transexualidad en un sentido indisociable de prácticas de corporización sexo genérica más o menos estables en el tiempo. Sinérgicamente, las producciones del campo médico abonaron a su fijación y estabilización, eslabonándose a discursos de la compasión, de la aberración moral y del peligro social. 
En base al análisis realizado, pueden identificarse tres modos de tratar y producir sentidos por parte del campo médico en torno a las iniciativas de corporización disidentes de las normas binarias de género: (a) la "demanda espontánea", (b) el saber forense y (c) la definición de límites legales y morales para la práctica médica. El primer modo refería a la irrupción de los pedidos de intervenciones quirúrgicas genitales en los consultorios médicos. La inesperada aparición de dichas demandas colocaba a profesionales de la salud frente a interrogantes sobre el vínculo entre cuerpo, identidad y técnica médica respecto a los cuales la única respuesta posible era la hipótesis de la aberración, la monstruosidad y la patología, revestida de un tono compasivo. El segundo reflejaba la elaboración de saberes clínicos en torno a "travestis" y "transexuales" al ser detenidas por parte de la policía en ocasión del ejercicio de la prostitución, o bien por el solo hecho de transitar por el espacio público. La vigencia de normativas criminalizantes de la prostitución, el travestismo y la homosexualidad en el espacio público les permitía a las instituciones forenses y policiales producir saberes sobre sus formas de vida y sus prácticas auto agenciadas de corporización. Esos saberes tenían un objetivo: producir un conjunto de técnicas a los fines de controlar la "desviación sexual", entendida como una conducta delictiva y contraria a la moral pública. El tercer modo identificado, elaborado desde la óptica de la medicina legal, tenía por fin establecer límites al ejercicio de la profesión médica dada la inexistencia de una normativa que impidiera legalmente a profesionales de la salud dispensar tratamientos hormonales "cruzados". Al constatar la existencia de profesionales de la salud receptivos de las demandas de tratamientos de corporización disidentes de las normas binarias de género, dicho documento tenía por objeto delimitar el campo de acción de la práctica médica en base a normas legales, clínicas y morales vigentes en ese momento.

La publicación de estos artículos dan cuenta que en las décadas de 1970 y 1980 los sujetos hacían uso de las biotecnologías disponibles para transformar la corporalidad en su dimensión somática a través del consumo autoadministrado de hormonas sintéticas, así como recurrían a profesionales de la salud con el fin de acceder a cirugías genitales. En definitiva, que los discursos criminalizantes y estigmatizantes de dichos deseos corporales no lograron impedir el desarrollo de unas prácticas de agenciamiento subjetivo y corporal disidente de las normas binarias de género.

La dinámica no solo regulatoria sino también productiva del proceso de consolidación de las categorías médicas del travestismo y la transexualidad permitió su afirmación como identidad subjetiva primero y como identidad política luego. Las organizaciones de travestis, transexuales y transgéneros de Argentina fueron las que elaboraron los contenidos de la ley 26.743, de identidad de género, que, desde 2012, permite no solo acceder a los cambios registrales sin ningún tipo de autorización médica, judicial o administrativa, sino también a los tratamientos médicos necesarios para construir una imagen corporal acorde a la identidad de género. El acceso a los tratamientos y tecnologías biomédicas fue definido como núcleo constitutivo y fundamental del concepto jurídico del derecho humano a la identidad de género que le dio sustento a la ley. Con su aprobación, los tratamientos fueron incluidos dentro del plan médico obligatorio, estableciendo su cobertura por parte de los tres subsistemas de salud.

La implementación de la Ley de Identidad de Género argentina en las instituciones de salud se presenta como un desafío no sólo en lo que atañe a la asignación de recursos 
humanos y sanitarios específicos sino también en lo que refiere a las representaciones y valoraciones de los y las profesionales de la salud. Prestando atención a dichas tensiones es que la indagación en perspectiva histórica de los sentidos que el campo médico asignó a las iniciativas de corporización disidentes de las normas binarias de género en las décadas de 1970 y 1980 resulta productiva para favorecer el desarrollo de una perspectiva despatologizante al interior de los equipos de salud, orientada por los principios de los derechos humanos y el derecho a la salud.

\section{NOTAS}

${ }^{1}$ El primer fallo judicial que autorizó un cambio de nombre y sexo registral en Argentina fue producido en 1997 por el Juzgado de Primera Instancia en lo Civil y Comercial n.8 de Quilmes. En el proceso judicial intervinieron como peritos un médico legista, dos psicólogos y un psiquiatra. Hasta la aprobación de la ley n.26.743, de identidad de género, en 2012, los cambios de nombre y sexo registral y el acceso a cirugías genitales requerían de una autorización judicial en las que la asignación de los diagnósticos de transexualismo o trastorno de la identidad de género a través de pericias médico psiquiátricas eran condición necesaria (Farji Neer, 2017).

${ }^{2}$ En 1852 se crea la Facultad de Medicina y el Consejo de Higiene Pública (luego llamado Departamento Nacional de Higiene). En 1875 se funda el Círculo Médico Argentino y en 1883, la Secretaría de Asistencia Pública (Nouzeilles, 2000, p.35).

${ }^{3}$ Siguiendo a Pablo Ben (2012), la magnitud que adquirió la demanda de sexo por dinero por parte de varones fue resultado de la explosión demográfica ligada al desarrollo de un sistema moderno de transporte y a la migración masiva. La explosión del fenómeno del sexo comercial, entre 1850 y 1950, no fue exclusivo de Buenos Aires sino de un gran número de ciudades a nivel mundial.

${ }^{4}$ En 1873 Ramos Mejía fundó el Círculo Médico Argentino, entre 1888 y 1892 fue diputado nacional y entre 1893 y 1898, presidente del Departamento Nacional de Higiene. Sus obras Las neurosis de los hombres célebres, La locura en la historia y Las multitudes argentinas, escritas entre 1878 y 1899 , fueron piezas fundamentales del pensamiento higienista local (Nouzeilles, 2000).

5 Jefe de servicio de cirugía del Hospital de Agudos "Cosme Argerich", hospital público de la Ciudad de Buenos Aires, entre 1944 y 1966.

${ }^{6}$ Revista de la Asociación Médica Argentina, fundada en 1894.

\section{REFERENCIAS}

ACHA, Omar; BEN, Pablo.

Amorales, patoteros, chongos y pitucos: la homosexualidad masculina durante el primer peronismo [Buenos Aires, 1943-1955]. Trabajos y Comunicaciones, Segunda Época, n.30-31. p.217260. 2004-2005.

BAO, Daniel.

Invertidos sexuales, tortilleras, and maricas machos: the construction of homosexuality in Buenos Aires, Argentina, 1900-1950. Journal of homosexuality, v.24, n.3-4. p.183-220. 1993.

BARBOSA, Bruno Cesar.

"Doidas e putas": usos das categorias travesti e transexual. Sexualidad, Salud y Sociedad: Revista Latinoamericana, n.14, p.352-379. 2013.
BARBOSA, Bruno Cesar.

Imaginando trans: saberes e ativismos em torno das regulações das transformações corporais do sexo. Tesis (Doctorado en Antropología Social) Universidade de São Paulo, São Paulo. 2015.

BEN, Pablo.

Historia global y prostitución porteña: el fenómeno de la prostitución moderna en Buenos Aires, 1880-1930. REMS, n.5-6, p.13-26. 2012.

BENJAMIN, Harry.

The transsexual phenomenon. New York: Julian Press. 1966.

BENTO, Berenice.

A reinvenção do corpo: sexualidade e gênero na experiência transexual. Rio de Janeiro: Garamond. 2006. 
BILLINGS, Dwight; URBAN, Thomas.

La construcción socio-médica de la transexualidad: interpretación y crítica. In: Nieto, José Antonio (Comp.). Transexualidad, transgenerismo y cultura: antropología, identidad y género. Madrid: Talasa. p.91-121. 1998.

CANO, Gabriela.

Amelio Robles, andar de soldado viejo: masculinidad (trangénero) en la Revolución Mexicana. Debate Feminista, v.39, p.14-39. abr. 2009.

CASTEL, Pierre-Henri.

Algumas reflexões para estabelecer a cronologia do "fenômeno transexual" (1910-1995). Revista Brasileira de História, v.21, n.41, p.77-111. 2001.

CAULDWELL, David O.

Psychopathia transexualis. In: Stryker, Susan; Whittle, Stephen (Ed.). The transgender studies reader. New York: Routledge. p.40-44. 2006.

CIANCIO, María Belén; GABRIELE, Alejandra. El archivo positivista como dispositivo visualverbal: fotografía, feminidad anómala y fabulación. Mora (Buenos Aires), v.18, n.1, p.2944. 2012.

COLEMAN, Eli et al.

Standards of care for the health of transsexual, transgender, and gender-nonconforming people, version 7. International Journal of Transgenderism, v.13, n.4, p.165-232. 2012.

CUTULI, María Soledad.

Maricas y travestis: repensando experiencias compartidas. Revista Sociedad y Economía, n.24, p.183-204. 2013.

DE VEYGA, Francisco.

La inversión sexual adquirida: Tipo de invertido profesional. Tipo de invertido por sugestión. Tipo de invertido por causa de decaimiento mental. In: Archivos de Psiquiatría, Criminología y Ciencias Afines. Buenos Aires: Talleres Gráficos de la Revista Nacional. p.193-208. 1903.

\section{DE VEYGA, Francisco.}

Invertido sexual imitando la mujer honesta. In: Archivos de Psiquiatría, Criminología y Ciencias Afines. Buenos Aires: Talleres Gráficos de la Revista Nacional. p.368-374. 1902.

DI SEGNI, Silvia.

Sexualidades: tensiones entre la psiquiatría y los colectivos militantes. Buenos Aires: Fondo de Cultura Económica. 2013.

DOVIO, Mariana Ángela.

El caso de la 'mala vida' en la Revista de Criminología, Psiquiatría y Medicina Legal (1914-1927) en Buenos Aires: entre la peligrosidad y la prevención. Historia del Derecho, n.43, p.1-29. 2012.
FARJI NEER, Anahí.

Travestismo, transexualidad y transgeneridad en los discursos del Estado argentino, desde los Edictos Policiales hasta la Ley de Identidad de Género. Ciudad Autónoma de Buenos Aires: Teseo. 2017.

FAUSTO-STERLING, Anne.

Cuerpos sexuados. Barcelona: Melusina. 2006.

GENTILI, Rafael Amadeo.

...me va a tener que acompañar: una visión crítica sobre los Edictos Policiales. Buenos Aires: CISALP. 1995.

HAUSMAN, Bernice.

Changing sex: transsexualism, technology, and the idea of gender. Durham: Duke University Press. 1995.

HIRSCHFELD, Magnus.

Selections from the transvestites: the erotic drive to cross-dress. In: Stryker, Susan; Whittle, Stephen (Ed.). The transgender studies reader. New York: Routledge. p.28-39. 2006.

INSAUSTI, Santiago J.

Selva, plumas y desconche: un análisis de las performances masculinas de la feminidad entre las locas del Tigre durante la década del ochenta. Revista Latinoamericana de Estudios sobre Cuerpos, Emociones y Sociedad, v.3, n.7, p.29-42. 2011.

KESSLER, Suzanne.

The medical construction of gender: case management of intersexed infants. Signs, v.16, p.3-26. 1990 .

KRAFFT-EBING, Richard.

Selections from psychopathia sexualis with special reference to contrary sexual instinct: a medico-legal study. In: Stryker, Susan; Whittle, Stephen (Ed.). The transgender studies reader. New York: Routledge. p.21-27. 2006.

KVITKO, Luis Alberto.

La situación del médico frente al tratamiento hormonal de travestis y transexuales: consideraciones jurídicas, medicolegales y deontológicas. La Semana Médica, v.161, n.10, p.350-358. 1982.

LEITE JR., Jorge.

Nossos corpos também mudam: sexo, gênero e a invenção das categorias "travesti" e "transexual" no discurso científico. Tesis (Doctorado en ciencias sociales) - Pontifícia Universidade Católica de São Paulo, São Paulo. 2008.

LENCIONI, Leo.

Aplicación del urocitograma en el estudio endocrino de casos de travestismo y transexualismo. La Semana Médica, v.158, n.14, p.510-513. 1981. 
MENDIARA, Irina.

Identidades huidizas: peligros sexuales en la formación del discurso médico legal. Tesis (Licenciatura en Antropología) - Universidad de Buenos Aires, Buenos Aires. 2002.

MEYEROWITZ, Joanne Jay.

How sex changed: a history of transsexuality. Cambridge: Harvard University Press. 2002.

MIRANDA, Marisa.

Controlar lo incontrolable: una historia de la sexualidad en Argentina. Buenos Aires: Biblos. 2011.

NOUZEILLES, Gabriela.

Ficciones somáticas: naturalismo, nacionalismo y políticas médicas del cuerpo (Argentina 18801910). Buenos Aires: Beatriz Viterbo. 2000.

PRECIADO, Beatriz (Paul B.).

Testo yonki. Madrid: Espasa. 2008.

ROHDEN, Fabiola.

Dualismos de género en la era de los nuevos usos sociales de la tecnociencia y la biología molecular. In: Cepeda, Agustina; Rustoyburu, Cecilia (Comp.). De las hormonas sexuadas al viagra: ciencia, medicina y sexualidad en Argentina y Brasil. Mar del Plata: EUDEM. p.35-74. 2014.

RUBIN, Henry.

Self-made men: identity and embodiment among transsexual men. Nashville, TN: Vanderbilt University Press. 2003.
RUSSO, Jane.

A terceira onda sexológica: medicina sexual e farmacologização da sexualidade. Sexualidade, Saúde e Sociedade, n.14, p.172-194. 2013.

SABSAY, Leticia.

Fronteras sexuales: espacio urbano, cuerpos y ciudadanía. Buenos Aires: Paidós. 2011.

SALESSI, Jorge.

Médicos maleantes y maricas: higiene, criminología y homosexualidad en la construcción de la nación argentina (1871-1914). Rosario: Beatriz Viterbo. 1995.

SIMONETTO, Patricio.

Intimidades disidentes: intersecciones en las experiencias de homosexuales y lesbianas en Buenos Aires durante los sesenta y setenta. Trashumante: Revista Americana de Historia Social, n.11, p.28-50. 2018.

SIMONETTO, Patricio.

La moral institucionalizada: reflexiones sobre el Estado, las sexualidades y la violencia en la Argentina del siglo XX.e-l@tina Revista Electrónica de Estudios Latinoamericanos, v.14, n.55, p.1-23. 2016.

YÓDICE, Arnaldo.

Aguafuerte quirúrgica. El Día Médico, p.295-296. 25 mar. 1971.

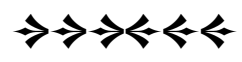

